\title{
Chronic non-puerperal uterine inversion: a rare case report
}

\section{Hanslata Gehlot, Praveen Kumar Choudhary, Seema Sharma*}

Department of Obstetrics and Gynaecology, Dr. S. N. Medical College, Jodhpur, Rajasthan, India

Received: 14 March 2016

Accepted: 11 April 2016

\section{*Correspondence:}

Dr. Seema Sharma,

E-mail: drseemasharma10@outlook.com

Copyright: (C) the author(s), publisher and licensee Medip Academy. This is an open-access article distributed under the terms of the Creative Commons Attribution Non-Commercial License, which permits unrestricted non-commercial use, distribution, and reproduction in any medium, provided the original work is properly cited.

\section{ABSTRACT \\ Uterine inversion though a rare entity but whenever diagnosed it is mostly seen in post partam cases. Chronic uterine inversion in non-parturient female is even rarer. Here we report such a case of chronic uterine inversion in non- puerperal period. Treatment depends on the associated pathology and the stage of the inversion. In our case we performed abdominal hysterectomy.}

Keywords: Chronic uterine inversion, Non-puerperal period

\section{INTRODUCTION}

Uterine inversion is defined as the passage of the uterine fundus through the endometrial cavity and cervix, so that the uterus is turned inside out. Although rare, it is of two types which can occur in two distinct clinical situations. First is the acute type which almost always occurs in the immediate postpartum period. It is associated with severe pain, post-partam haemorrhage and acute anaemia. The other variant is the chronic inversion which is insidious in onset. It is usually associated with vaginal discomfort, irregular vaginal bleeding, vaginal discharge and anaemia. ${ }^{1-6}$ Non puerperal inversion is often chronic, although Das has reported $8.6 \%$ of non-puerperal inversion as sudden onset.?

Non-puerperal uterine inversion accounts for nearly $5 \%$ of all uterine inversions and is generally associated with exteriorization of uterine cavity tumours. ${ }^{8-12}$ Another study states that it accounts for nearly one sixth of all cases. It is mostly associated with tumour at the fundus of the uterus. ${ }^{13,14}$ Diagnosing a case of non-puerperal uterine inversion is often difficult and requires high index of suspicion.

\section{CASE REPORT}

A 35 years old female first reported in our hospital in emergency ward as referred case from a peripheral hospital on account of procidentia. She had complaints of backache and dragging sensation in lower abdomen since one month. Pain aggravated during voiding and standing position and relieved on lying down position. She also had foul smelling discharge per vaginum since 15 days and bleeding per vaginum since 15 days. She complained of mass coming out introitus since one week. There was history of vomiting and diarrhea 8 days back which lasted for 2 days.

Patient had 3 full term home vaginal delivery and none of them was associated with any complication. Last delivery was 11 years back. Patient could not ascertain her last menstrual period but there was continuous bleeding since 15 days. Her previous cycles were regular with flow for 6-7 days once in 30 days. She had history of laparoscopic sterilization 10 years back. There was no significant past history and no significant family history.

On admission patient was conscious, oriented, though she was anxious. Patient was thin built. She was afebrile her pulse rate was 120 / min with moderate volume and blood pressure was $130 / 80 \mathrm{~mm}$ of $\mathrm{Hg}$. Cardiovascular and 
Respiratory systems were within normal limits. She was pale. Viral markers (HIV, HBsAg and VDRL) were negative.

On per abdominal examination it was soft, tenderness present in lower abdomen. Laparoscopic scar was present. On local examination (Figure 1) a large offensive necrotic mass of size almost $6 \times 6 \mathrm{~cm}$ attached to a smooth surfaced globular mass with bossellated surface, blackish necrosed area, patchy white flakes with slough and bleeds on touch. Mucopurulent discharge was present. On per vaginal examination a large non-reducible necrotic mass of size $6 \times 6 \mathrm{~cm}$ appeared to be attached to the fundus of uterus. Cervical rim was not felt. Mass was friable and bleeds on touch. On uterine sound, no uterine cavity could be appreciated. On per rectal examination uterus could not be felt rather a vacuum was felt anteriorly. Mass could not be reposited into vagina and bleeding was present on attempting reposition.

On investigation, her hemoglobin was $7.3 \mathrm{gm} \%$, TLC14,650. Renal and liver function tests all were within normal limits. Coagulation profile was normal. Thyroid profile was also normal. Her chest X Ray was suggestive of fibrotic band in Right Medio lateral lobe of lung. So further High Resolution Computed tomography (HRCT) of thorax was done which revealed old healed bronchopulmonary infection. ESR- Normal $(10 \mathrm{~mm} / \mathrm{hr})$. Sputum for AFB was negative. Ultrasound of abdomen and pelvis revealed non visualization of uterus in the pelvis and $U$ shaped cavity noted in the region of uterine cavity.

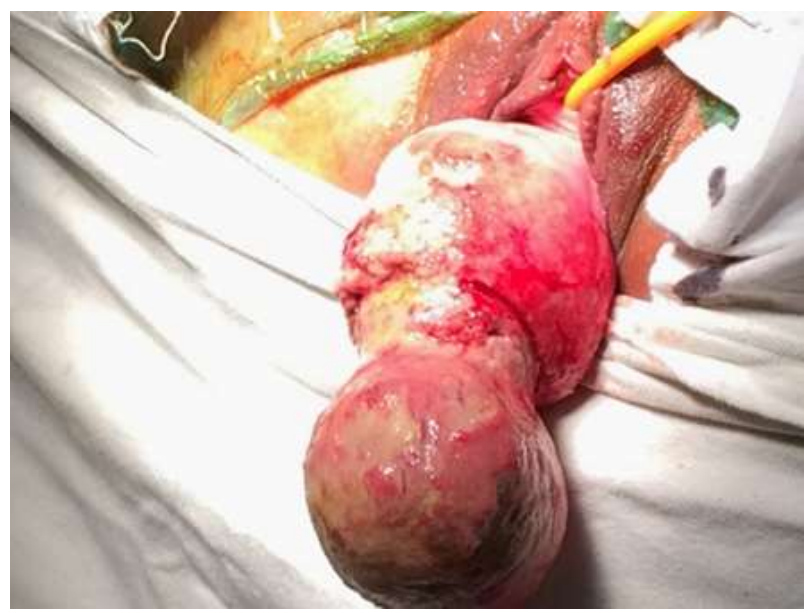

Figure 1: Large uterine fibroid present at the fundus of uterus inverted outside and present outside vaginal introitus.

Patient was managed on broad spectrum antibiotics. Selfretaining Foley's catheter inserted. Two units of packed cells were given for correction of anemia. Daily dressing of the mass with betadine, magnesium sulphate and glycerin was done which gradually reduced the edema and the mass could be reduced in vagina (initially the mass was not reducible).
After clearance from physician patient was taken for abdominal surgery. Vaginal removal of the tumor was attempted but it was sessile, so reposition was first performed then followed by total abdominal hysterectomy (Figure 2).

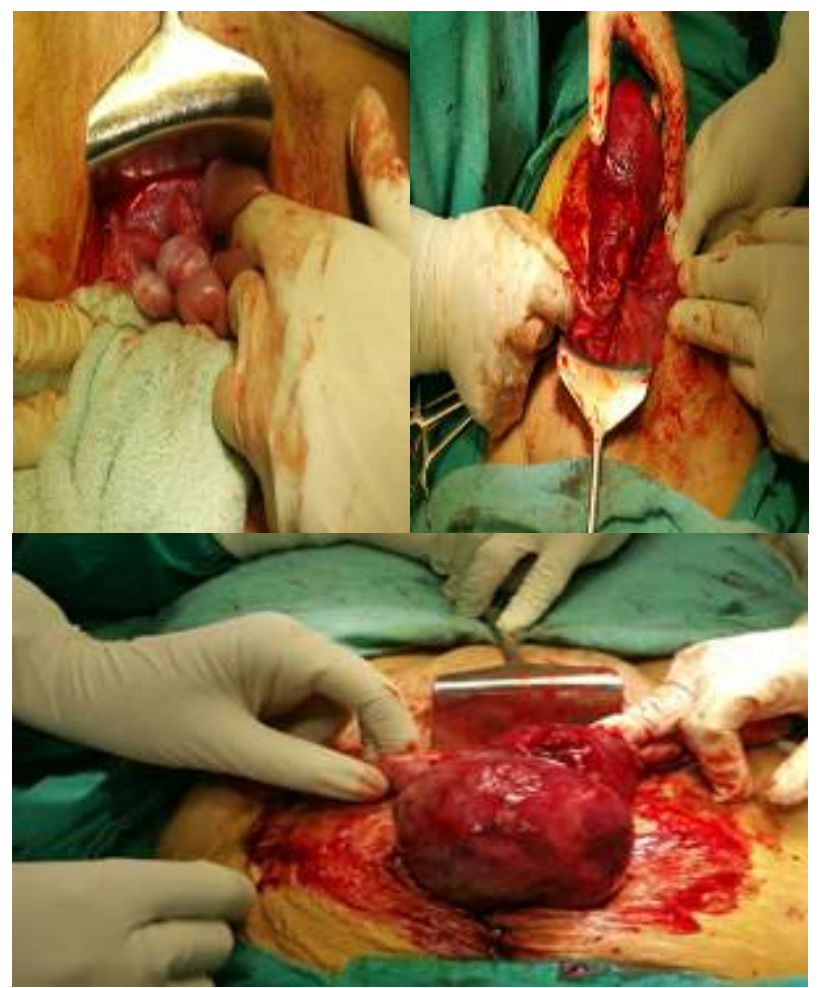

Figure 2: Intraoperative findings suggestive of inverted uterine fundus.

Post-operative period was uneventful. Patient was discharged on the $6^{\text {th }}$ postoperative day and was followed up at 4 weeks. Histopathological report confirmed the diagnosis of chronic uterine inversion and myoma of uterus.

\section{DISCUSSION}

Chronic non-puerperal uterine inversion is a rare finding in women with less than 200 cases reported in the literature since $1887 .{ }^{10,11}$ Mostely, it is associated with tumor of the fundus, either a submucosal fibroid or sometimes a leiomyosarcoma. ${ }^{12-17}$ In our case it was a sessile non pedunculated myoma of the fundus of uterus. Inversion of the myomatous uterus is due to both thinning and weakening of the uterine wall at the seat of the tumor's implantation. It is also suggested that sudden emptying of the uterine cavity which was distended by a large tumor and dilation of cervix play role in chronic uterine inversion. ${ }^{8,18-20}$ This is due to the pressure atrophy, which is more marked with larger tumor and the contractions of the uterine musculature which are excited by the prolapse of the tumor into the cavity of the organ. A classification of genital inversion has been described: ${ }^{2}$ 
Stage 1: Inversion of the uterus is intrauterine or incomplete. The fundus remains within the cavity.

Stage 2: Complete inversion of the uterine fundus through the fibro muscular cervix.

Stage 3: Total inversion, whereby the fundus protrudes through the vulva.

Stage 4: The vagina is also involved with complete inversion through the vulva along with an inverted uterus.

Diagnosing a case of uterine inversion in non-puerperal cases often presents a clinical challenge to the treating gynaecologist. It requires a high index of suspicion. The female may present with complaints of lower abdominal pain and tenderness, vaginal bleeding, urinary frequency, dysuria and urgency. On examination one may find a mass coming out through the cervix without definite margins of a cervix. Absence of the uterine fundus or fundal dimpling during bimanual or rectal examinations are strongly suggestive of the diagnosis. The openings of fallopian tubes may at times but not always be visible as the endometrium surface is dragged outside. Constriction ring of cervix may be felt in complete uterine inversion.

Ultrasound scan is most of the times is the first imaging modality which assists in diagnosing the case. ${ }^{16,17}$ The suggestive features include indentation of the fundal area and depressed longitudinal groove extending up to the centre of the inverted uterus.

When available, Magnetic Resonance Imaging (MRI) can be very useful. The features will include: "U" shaped uterine cavity, thickened and inverted uterine fundus on sagittal section and "bull's eye" configuration on an axial image. $^{21,22}$ MRI was not performed in our case because of financial hurdles.

Frozen section of the vaginal mass has been used by some authors for the diagnosis. Demonstration of the endometrium on the surface of the mass will confirm the diagnosis. Biopsy of the mass has definite place if an associated malignancy is suspected. Takano et al summarized 88 reported cases of nonpuerperal uterine inversion; 81 (92\%) of these were associated with uterine tumors, of which $20 \%$ were malignant. This emphasizes the need to perform biopsies prior to definitive treatment. $^{18}$

Various surgical methods for treatment of chronic uterine inversion have been described in literature. Huntington's operation and Haultain's operation are done by abdominal route, while Spinelli's and Kustner's technique are done vaginally.

The morbidity and mortality associated with uterine inversion correlate with the degree of haemorrhage, the rapidity of diagnosis, and the effectiveness of treatment.
Some authors suggest transvaginal excision of the tumor mass before abdominal hysterectomy.

\section{CONCLUSION}

Chronic uterine inversion is a rare condition that is difficult to manage even for the experienced gynaecologists. Uterine inversion has a good prognosis when managed in timely correct manner. The treatment for chronic uterine inversion is surgical that includes both abdominal and vaginal approaches. However, need for preservation of fertility excluding malignancy might be important in selected cases.

\section{ACKNOWLEGEMENTS}

We acknowledge the help our entire team of obstetricians, operation theatre and ICU staff for their help and cooperation. The woman and her whose story is told in this case report cooperated in our work signed permission for its publication.

\section{Funding: No funding sources Conflict of interest: None declared \\ Ethical approval: Not required}

\section{REFERENCES}

1. Aspevik RK, Haffner J. Puerperal inversion of the uterus [in Norwegian]. Tidsskr Nor Laegeforen. 1989;109:1403-4.

2. Barhmi R, Ferhati D, Nabil S, et al. Complete nonobstetrical uterine inversion [in French]. Gynecol Obstet Biol Reprod. 1995;24:155-7.

3. Gowri V. Uterine inversion and corpus malignancies: a historical review. Obstet Gynecol Surv. 2000;55:703-7.

4. Grischke EM, Wallwiener D, Bastert G. Puerperal uterine inversion with covered uterine rupture [in German]. Z Geburtshilfe Neonatol. 1999;203:123-5.

5. Salomon CG, Patek SK. Computed tomography of chronic nonpuerperal uterine inversion. J Comput Assist Tomogr. 1990;14:1024-6.

6. Tews G, Ebner T, Yaman C, Sommergruber M, Bohaumilitzky T. Acute puerperal inversion of the uterus treatment by a new abdominal uterus preserving approach. Acta Obstet Gynecol Scand. 2001;80:039-1040.

7. Das P. Inversion of the uterus. J Obstet Gynaecol Br Emp. 1940;47:527-48.

8. Dali M, Rajbhandari S, Shrestha S: Puerperal inversion of the uterus in Nepal: case reports and review of literature. J Obstet Gynaecol Res. 1997;23:319.

9. Fofie C, Baffoe P: Non-puerperal uterine inversion: a case report. Ghana Med J. 2010;44(2):79-81.

10. deVries M, Perquin DAM. Non-puerperal uterine inversion due to submucous-myoma in a young woman: a case report. Journal of Medical Case Reports. 2010;4:21. 
11. Gomez-Lobo V, Burch W, Khanna PC. Nonpuerperal uterine inversion associated with an immature teratoma of the uterus in an adolescent. Obstetrics \& Gynecology. 2007;110:491-3.

12. Charlie CK, Lubna C, Robert CM. Chronic nonpuerperal uterine inversion and necrosis: a case report. Journal of Medical Case Reports. 2010;4:381.

13. Eigbefoh JO, Okogbenin SA, Omorogbe F, Mabayoje PS. Chronic uterine inversion secondary to submucous fibroid: a case report. Nigerian Journal of Clinical Practice. 2009;12(1):106-7.

14. Lai FM, Tseng P, Yeo SH, Tsakok FHM. Non puerperal uterine inversion: a case report. Singapore Medical Journal. 1993;34:466-8.

15. Omololu OM, Rabiu KA, Quadri MA, Oyedeko MO, Fatogun YM. Non puerperaluterine inversion due to submucous fibroid: a case report. Nigerian PostgraduateMedical Journal. 2011;18(2):158-60.

16. $\mathrm{Hu} \mathrm{CF}$, Lin $\mathrm{H}$. Ultrasound diagnosis of complete uterine inversion in a nulliparouswoman. Acta Obstetricia et Gynecologica Scandinavica. 2012;91(3):379-8.

17. Krissi H, Peled Y, Efrat Z, Goldshmit C. Ultrasound diagnosis and com-prehensive surgical treatment of complete non-puerperal uterineinversion. Archives of Gynecology and Obstetrics. 2011;283(Suppl1):111-4.

18. Takano K, Ichikawa Y, Tsunoda H, Nishida M. Uterine inversion caused by uterine sarcoma: a case report. Jpn J Clin Oncol. 2001;31:39-42.

19. Lascarides E, Cohen M. Surgical management of the non-puerperal inversion of the uterus. Obstet Gynecol. 1968;32:376-81.

20. Rattary CA, Parris CN, Chisholm G, Coard KC. Complete nonpuerperal uterine inversion as a result of a uterine sarcoma. West Indian Med J. 2000;49:245-7.

21. Occhionero M, Restaino G, Ciuffreda M, Carbone A, Sallustio G, Ferrandina G. Uterine inversion in association with uterine sarcoma: a case report with MRIfindings and review of the literature. Gynecologic and ObstetricInvestigation. 2012;73(3):260-4.

22. Lewin JS, Bryan PJ. MR imaging of uterine inversion. J Comput Assist Tomogr. 1989; 13: 357 359. RA Krenning. Nonpuerperal uterine inversion. Review of literature. Clin Exp Obstet Gynecol. 1982;9:12-5.

Cite this article as: Gehlot $\mathrm{H}$, Choudhary $\mathrm{PK}$, Sharma S. Chronic non-puerperal uterine inversion: a rare case report. Int J Reprod Contracept Obstet Gynecol 2016;5:1629-32. 